\title{
Heterozygote Triplets. A Rare Case of Wilkie's Syndrome
}

\author{
Rigoberto Vidal, ${ }^{1}$ Federico Cuenca-Abente, ${ }^{2}$ Diego Ferro ${ }^{3}$ \\ ${ }^{1}$ Digestive tract surgery fellow, Hospital de Gastroenterología "Dr. Carlos Bonorino Udaondo". \\ ${ }^{2}$ Chief of foregut surgery, Hospital de Gastroenterología "Dr. Carlos Bonorino Udaondo". \\ ${ }^{3}$ Chief of general surgery, Hospital de Gastroenterología "Dr. Carlos Bonorino Udaondo". \\ Ciudad Autónoma de Buenos Aires, Argentina.
}

Acta Gastroenterol Latinoam 2020;50(4):485-490

Recibido: 06/03/2020 / Aceptado: 06/08/2020 / Publicado online: 14/12/2020

\section{Summary}

Wilkie's Syndrome is a rare cause of small bowel obstruction that rarely occurs in a familiar setting. We report a rare variant, related to heterozygote triplets in a case that underwent laparoscopic duodenojejunostomy to bypass the obstructed segment. During the patient's clinical evolution, we collected and discussed preoperative and post-operative studies. In addition, we performed a review of literature.

Key words. Superior mesenteric artery syndrome, Wilkie's syndrome, laparoscopic duodenojejunostomy.

Correspondencia: Rigoberto Vidal

Av. Caseros 2153 (C.P.: 1264). Ciudad Autónoma de Buenos Aires,

Argentina / Tel.: +541143064641

Correo electrónico: rigoberto_vidal@yahoo.com

\section{Trillizos heterocigotos. Un caso raro de síndrome de Wilkie}

\section{Resumen}

El Sindrome de Wilkie es una causa poco frecuente de obstrucción del intestino delgado que rara vez tiene una presentación familiar. Reportamos una variante inusual, que involucra trillizos heterocigotos en un caso que se sometió a duodeno yeyunostomía laparoscópica para sortear el segmento obstruido. Los estudios preoperatorios y postoperatorios fueron recolectados y discutidos durante la evolución clinica del paciente. Además, se realizó una revisión de la literatura.

Palabras claves. Sindrome de la arteria mesentérica superior, sindrome de Wilkie, duodenoyeyunostomía laparoscópica.

\section{Introduction}

Superior mesenteric artery syndrome (SMAS), or Wilkie's Syndrome, is one of the rare causes of small bowel obstruction. ${ }^{1}$ SMAS is a disorder characterized by a vascular compression of the duodenum leading to mechanical obstruction. ${ }^{2}$ Its prevalence ranges from 0.1 to $0.3 \% .^{1,3}$ SMAS has been described in a familiar setting, 
as well as in twins, suggesting a genetic predisposition to this syndrome. ${ }^{3,4}$ In this report, the genetic consultation ruled out genetic or hereditary association of the SMAS. To our knowledge, this is the first case of SMAS in heterozygote triplets.

\section{Case report}

A 25 years old woman, with diagnosis of chronic non-progressive encephalopathy, was referred to the E.R. with a history of weight loss associated with postprandial vomiting that intensified in the last 10 days. Nutritional consultation was performed with subjective global assessment score being $\mathrm{C}$ and body mass index (BMI) was 12.5 at the time of admission. The patient represents one of two triplets affected by this syndrome. Her sister was diagnosed with SMAS and treated at another institution. The third triplet is being studied at present. Upper endoscopy, esophageal manometry, and laboratory tests showed no abnormalities. The barium swallow test showed megaduodenum with a narrowing in the third portion (Figure 1).

A computed tomography angiography (CTA) was performed, confirming an aorto-mesenteric angle of $17.5^{\circ}$ with a distance of $8 \mathrm{~mm}$, both signs consistent with SMAS (Figures 2, 3, 4).

Due to intolerance of enteral feeding, parenteral nutrition was started. After six weeks, conservative treatment failed due to the persistence of vomiting. A surgical approach was indicated, performing a laparoscopic duodenojejunostomy (Figures 5, 6, 7).

Figure 1. Barium swallow. Megaduodenum with a fine narrowing in the third portion

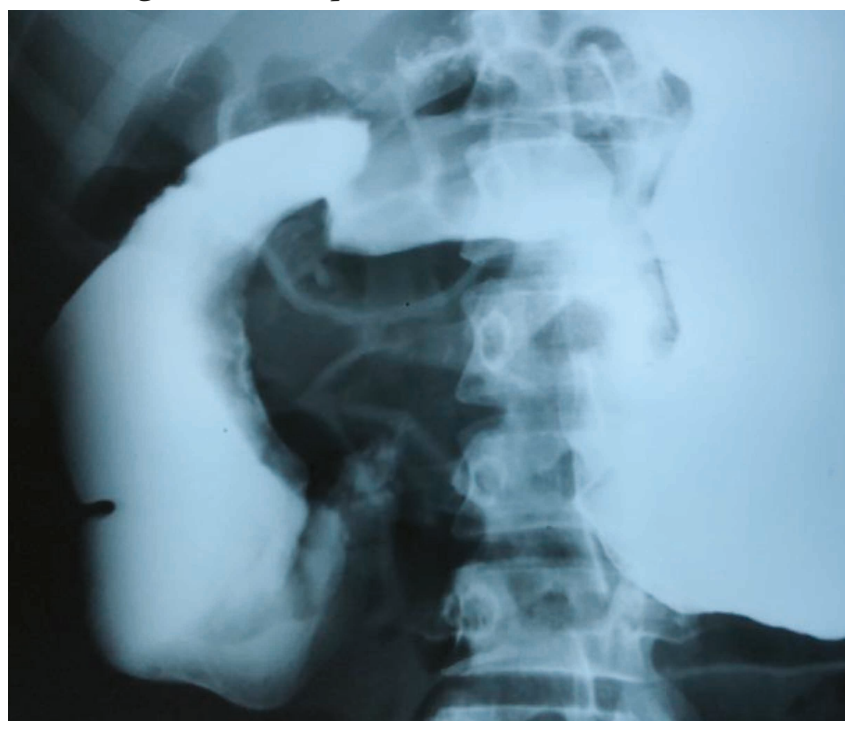

Figure 2. CTA. Aorto-mesenteric angle of $17.5^{\circ}$

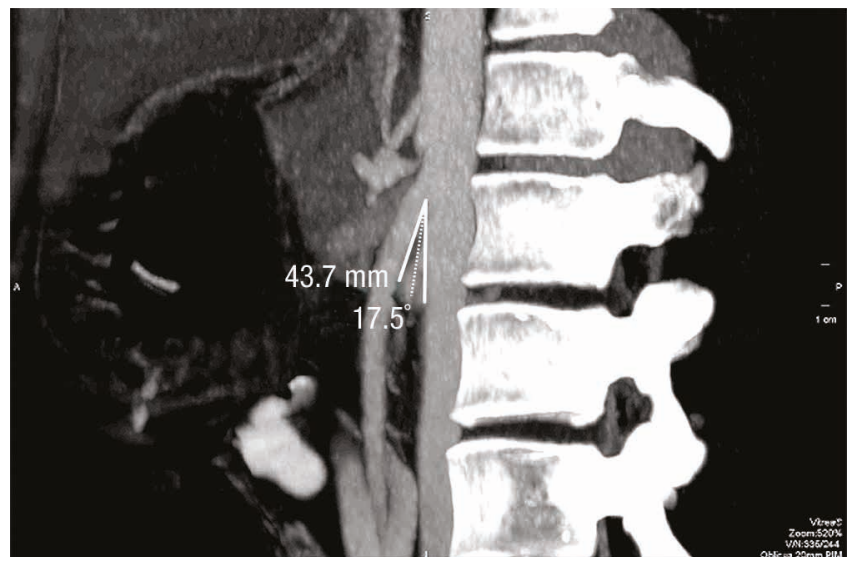

Figure 3. CTA. Aorto-mesenteric distance of $8 \mathrm{~mm}$

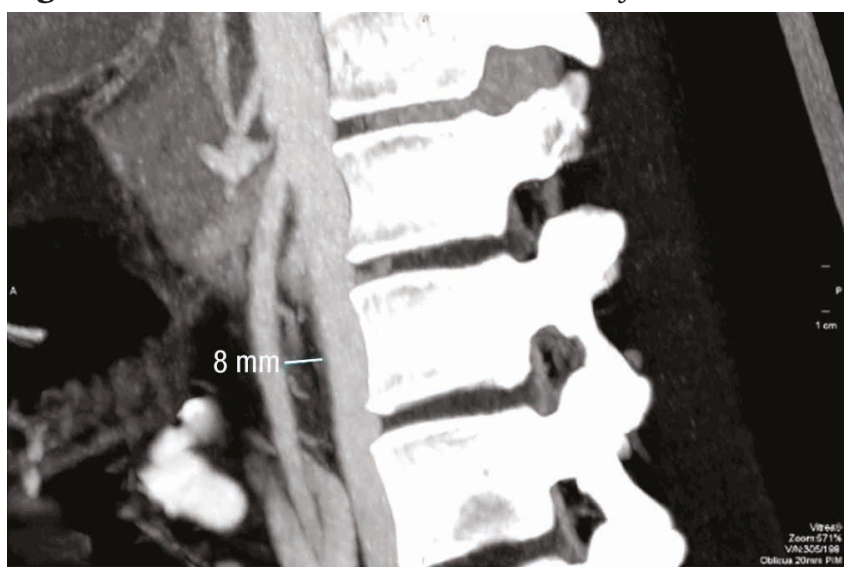

Figure 4. CTA 3D. Aorto-mesenteric angle of $17.5^{\circ}$

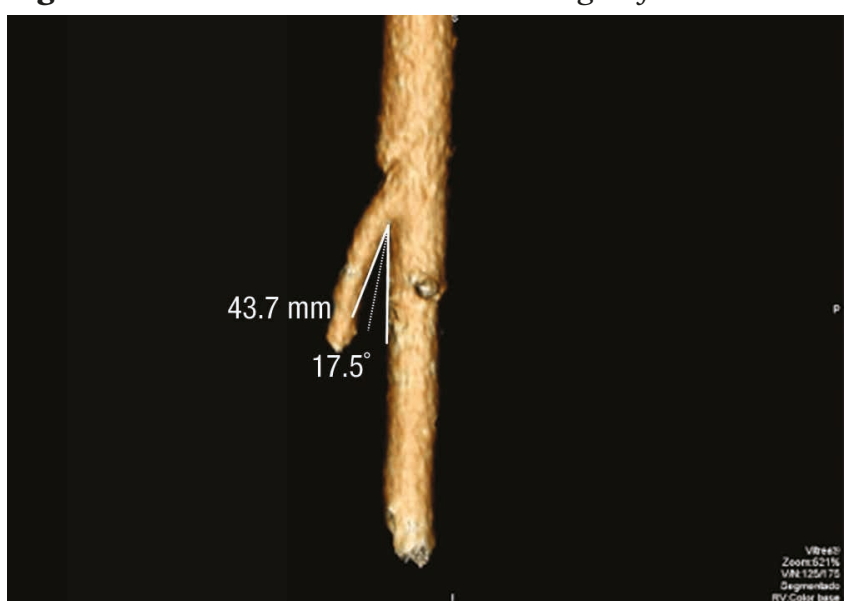

After twelve weeks, the patient was discharged with oral and parenteral nutrition.

Six months later, the patient's BMI was 19, presenting a total weight gain of $16 \mathrm{~kg}$. A new CTA was performed, showing an aorto-mesenteric angle of $44.2^{\circ}$ and a distance of $12 \mathrm{~mm}$. (Figures 8, 9, 10, 11, 12). 
Figure 5. Duodenojejunostomy. Distented stomach and inframesocolonic vision

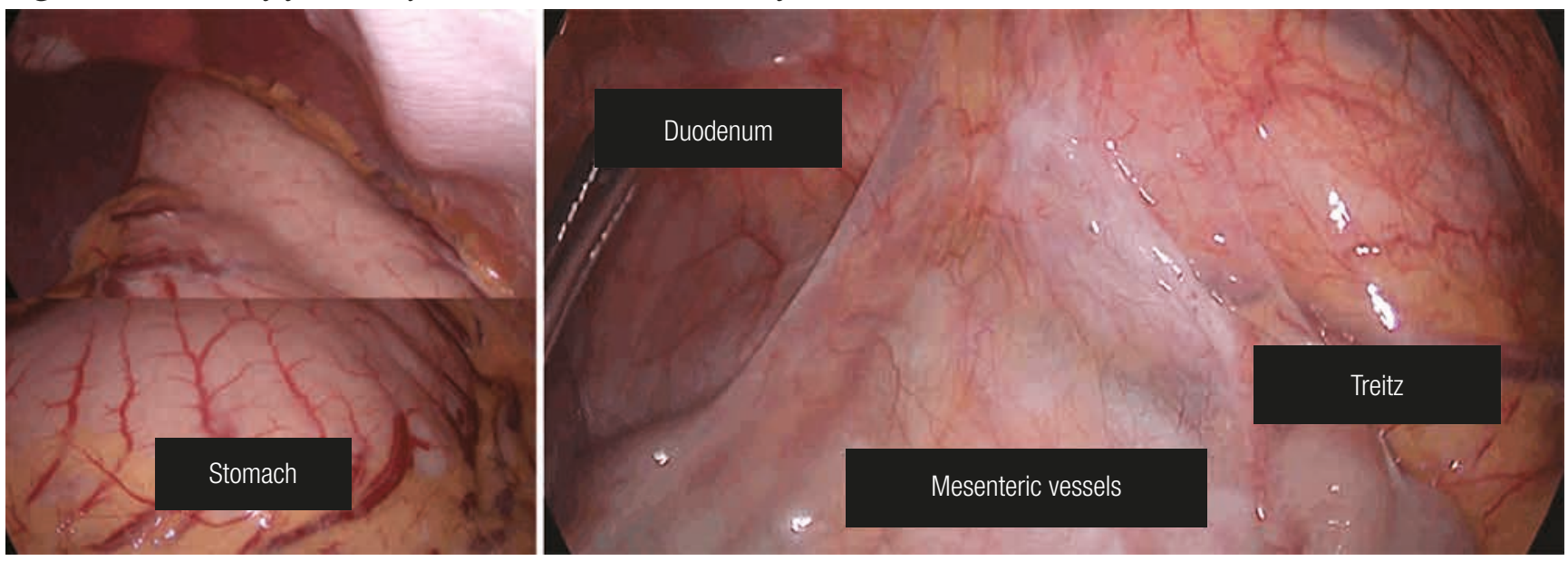

Figure 6. Duodenojejunostomy. Duodenal dissection and duodenoyeyunal anastomosis

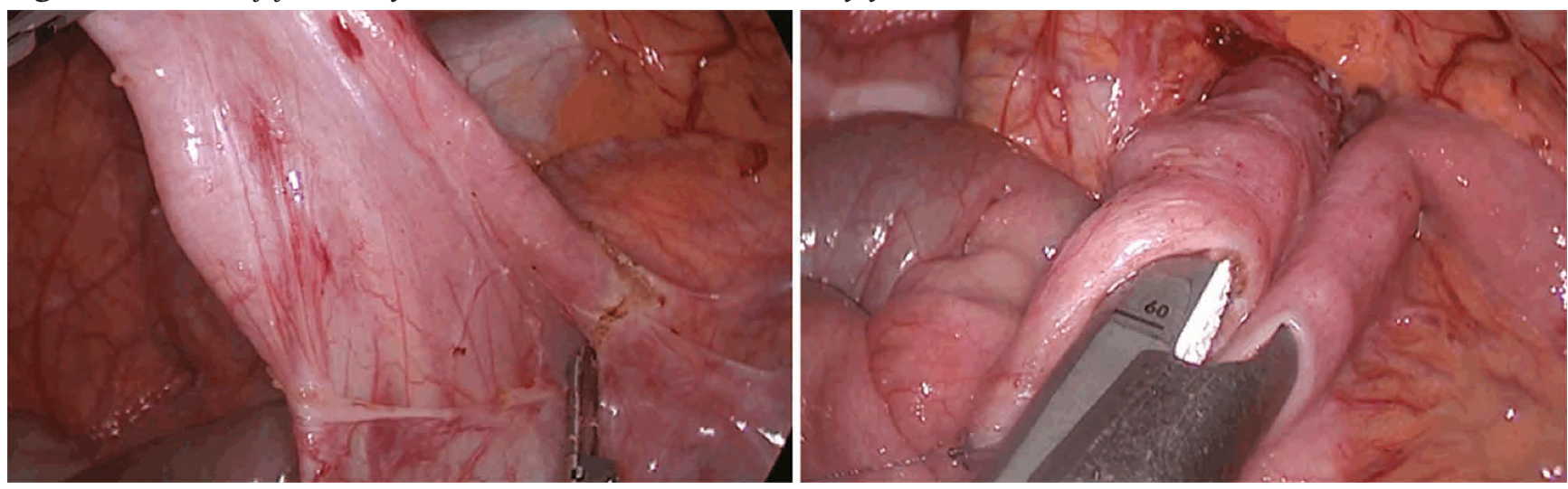

Figure 7. Duodenojejunostomy. Side by side anastomosis

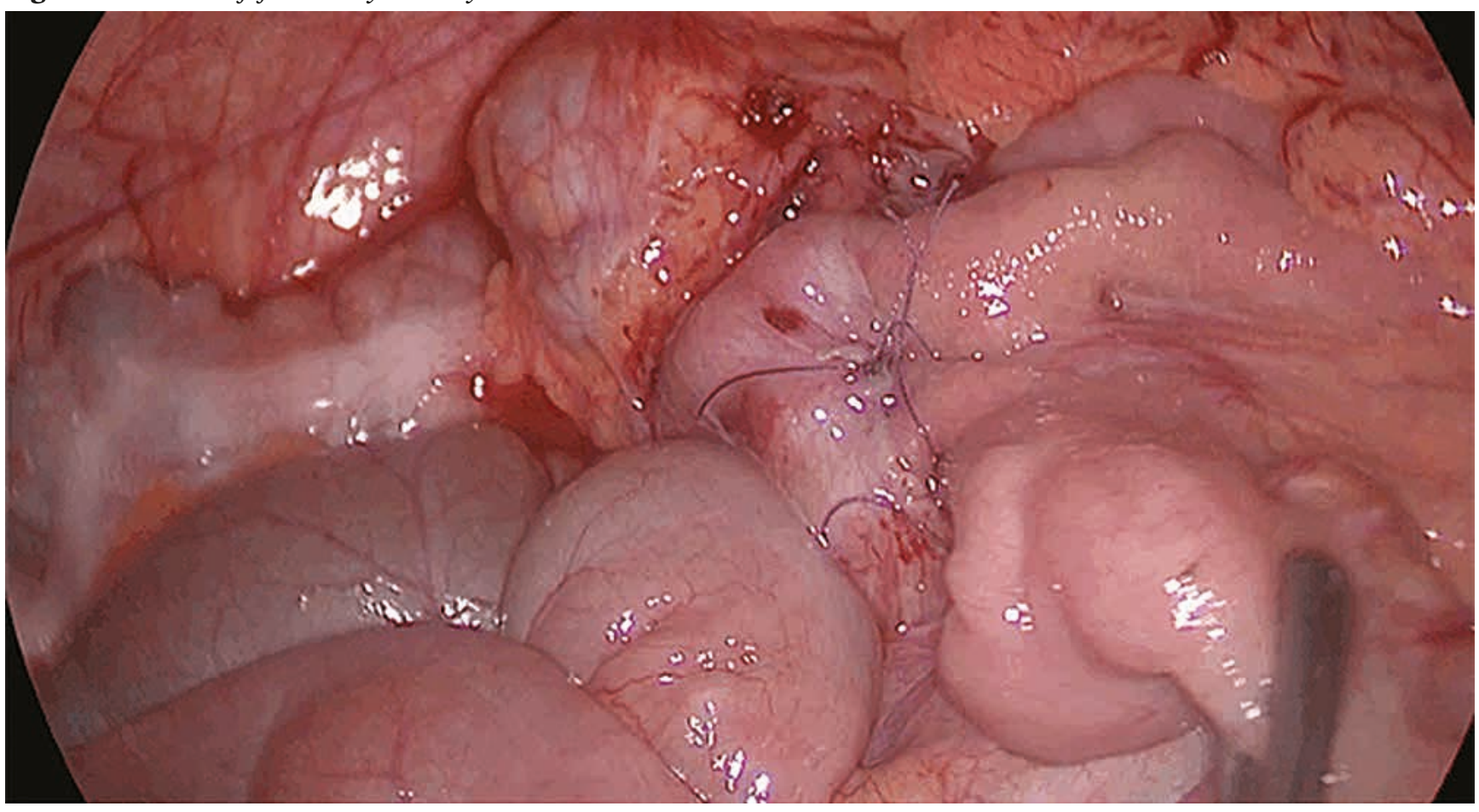


Figure 8. Post-surgical CTA. Aorto-mesenteric angle of $44.2^{\circ}$

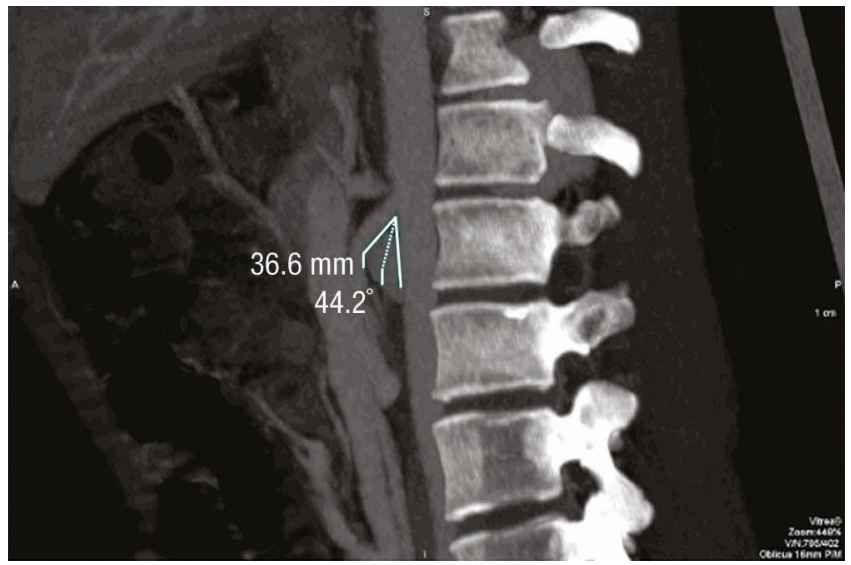

Figure 9. Post-surgical CTA. Aorto-mesenteric distance of $12 \mathrm{~mm}$

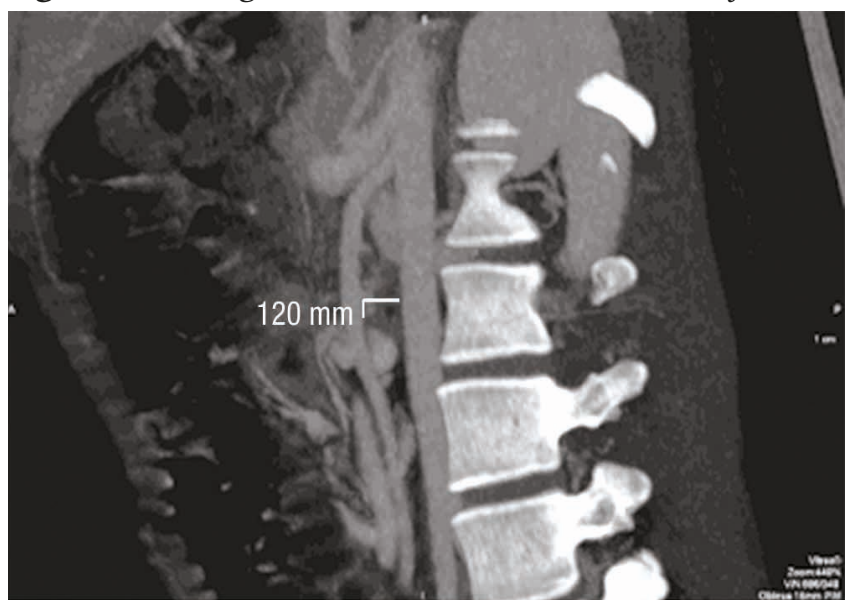

Figure 10. Post-surgical CTA 3D. Aorto-mesenteric angle of $44.2^{\circ}$

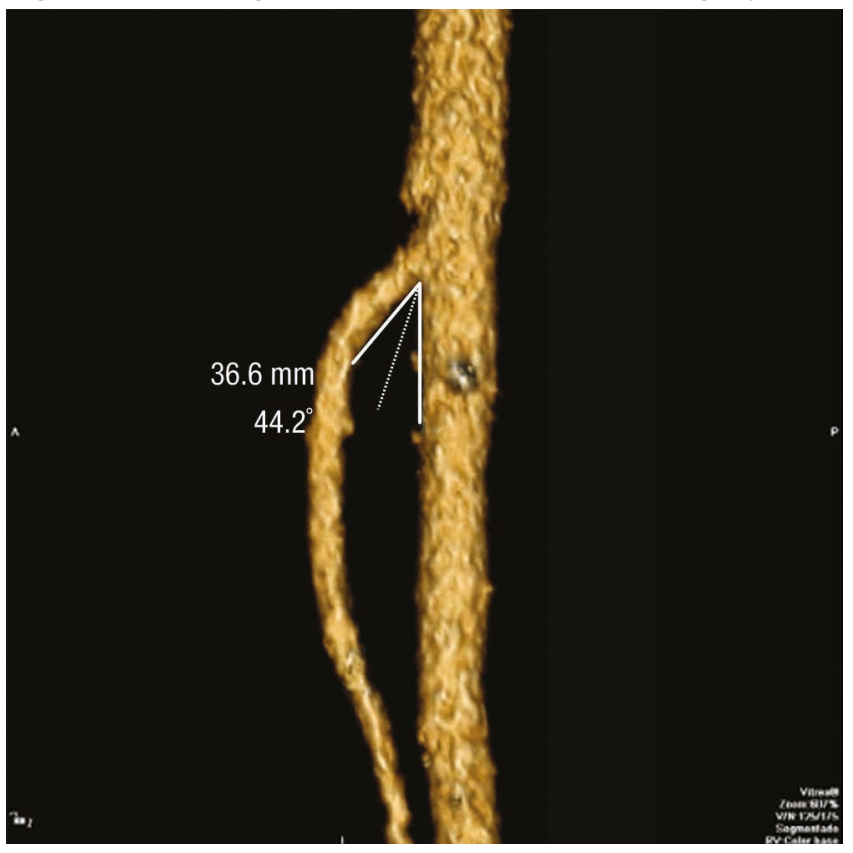

Figure 11. CTA pre-surgical aorto-mesenteric angle of $17.5^{\circ}$ compared with CTA post-surgical of $44.2^{\circ}$
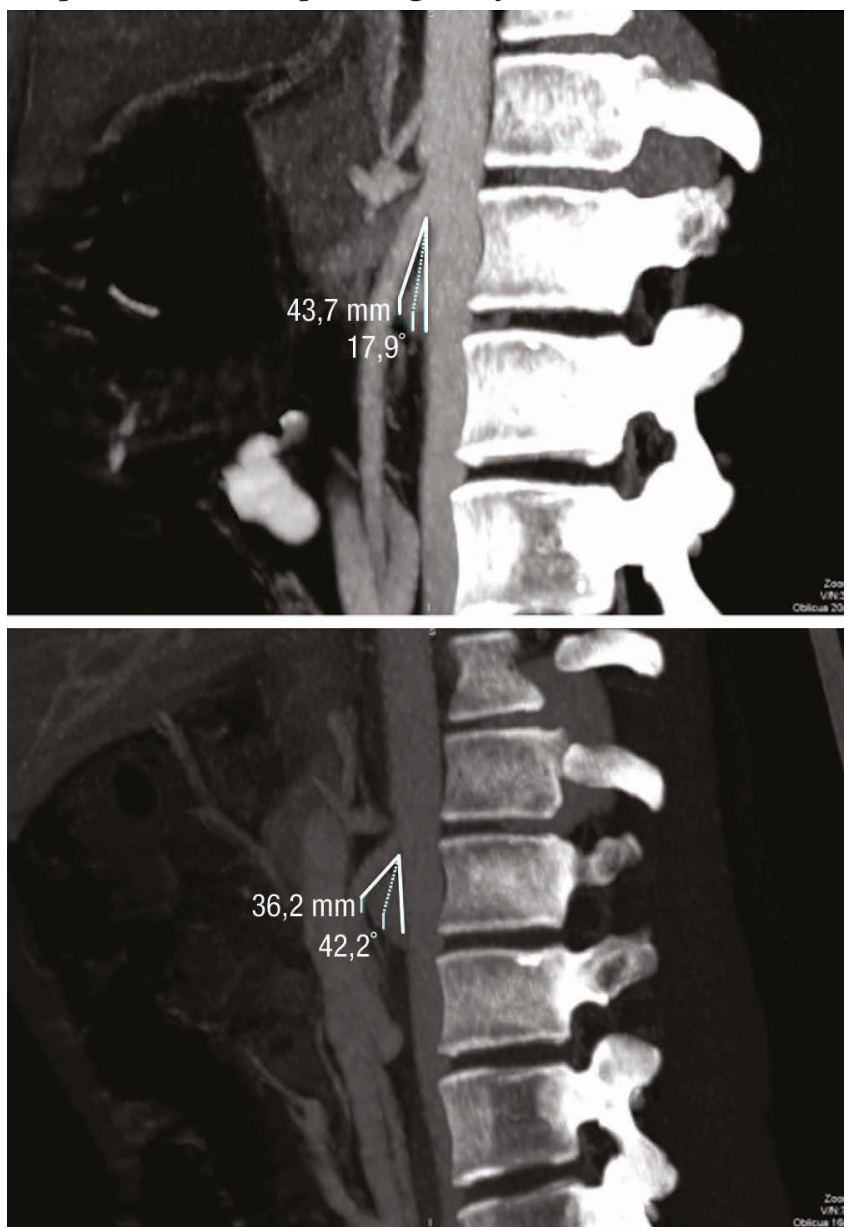

Figure 12. CTA $3 D$ pre-surgical aorto-mesenteric angle of $17.5^{\circ}$ compared with CTA $3 D$ post-surgical of $44.2^{\circ}$

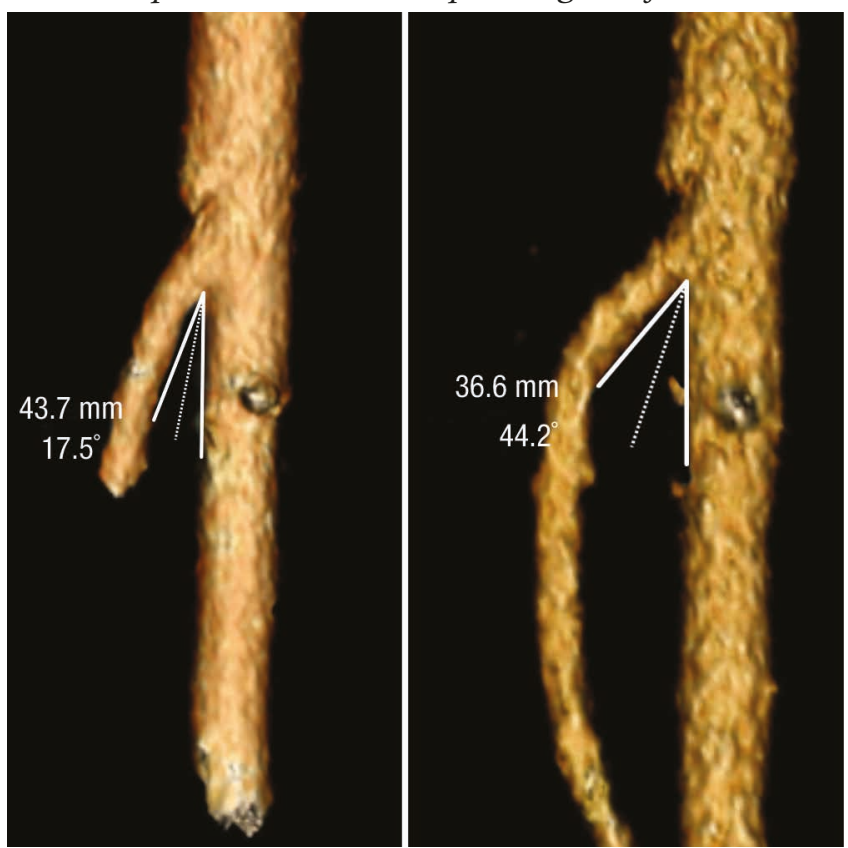




\section{Discussion}

First described by Rokitansky in $1842,{ }^{2}$ the SMAS involves the entrapment and obstruction of the third part of the duodenum between the superior mesenteric artery (SMA) and the aorta. In 1927, Wilkie et al. published the largest study on SMAS based on 75 cases in which the final conclusion was that duodenojejunostomy was the treatment of choice. ${ }^{5}$

SMAS is characterized by the compression of the third portion of the duodenum due to the narrowing of the space between the SMA and the aorta. This phenomenon is primarily attributed to a loss of the mesenteric fat pad, located in that area. ${ }^{2}$ Fat loss and secondary compression may be precipitated by progressive weight loss in clinical situations like malignancies, dietary disorders, or trauma. This syndrome may also result from surgical procedures that reduce the aorto-mesenteric angle, for example, ileo-anal pouch producing caudal traction of the mesentery or scoliosis correcting surgery. ${ }^{6}$ SMAS may also be seen in association with psychological symptoms.

The genetic predisposition to its development has been suggested in a report of its occurrence in identical twins; however, this phenomenon is subject to further research. ${ }^{8}$ Implicated congenital factors such as a short ligament of Treitz and/or a low implantation of the SMA have also been proposed. ${ }^{3}$

This disorder is a very rare condition and its incidence is considered to range between $0.2-0.3 \%{ }^{3}$ However, in patients with scoliosis who undergo corrective spinal surgery, its prevalence increases to $2.4 \%$. $^{9}$ The SMAS mortality rate is estimated to be $33 \% .^{10} \mathrm{~A}$ total of 400 cases have been reported in the literature in English with a slight prevalence in young female patients. ${ }^{2,7}$ SMAS should be considered when persistent vomiting is present, especially after a history of weight loss. ${ }^{1}$

Patients usually present a long history of unspecific abdominal symptoms: postprandial epigastric pain, nausea, vomiting, anorexia, weight loss, esophageal reflux, and bloating. The discomfort may be relieved by measures that reduce tension on the small bowel mesentery, such as left lateral decubitus, assuming a 'knee-chest' position. ${ }^{6}$ Dehydration and electrolyte abnormalities due to prolonged vomiting are not uncommon. ${ }^{1}$

For diagnostic purposes, upper gastrointestinal series, CTA, magnetic resonance, angiography, conventional angiography, ultrasonography, and endoscopy have all been described. The clinical diagnosis can be confirmed by radiologic studies in $95 \%$ cases. $^{11}$

The aorta-SMA angle in patients with SMAS has been reported to range from $6-22^{\circ}$ and the aorta-SMA distance to be between $2-8 \mathrm{~mm}$, compared with $25-60^{\circ}$ and $10-28 \mathrm{~mm}$ respectively in normal population. ${ }^{7,9,12-14}$ CTA with $3 \mathrm{D}$ reconstruction is a useful noninvasive diagnostic tool that may aid in confirming duodenal obstruction due to vascular compression.

A multidisciplinary team should approach these patients. The team should include gastroenterologists, interventional radiologists, dietitians, psychologists and surgeons. ${ }^{6}$

Although there is no consensus on the optimal therapeutic strategy for SMAS, conservative management is usually the first choice ${ }^{3}$ which should be administered for at least six weeks. ${ }^{10}$ Conservative treatment includes gastric decompression, fluid electrolytes imbalance correction, and nutritional support either through total parenteral or nasojejunal feeding. Conservative treatment also focuses on nutritional support aimed at restoration of retroperitoneal fat and weight gain, ${ }^{1}$ which may restore the SMA-aortic angle.

When conservative treatment fails, surgery is required. ${ }^{15}$ Different surgical techniques have been described to treat SMAS. Proposed by Strong, the transection of the ligament of Treitz, and subsequent mobilization of the duodenum, was first prescribed. ${ }^{7}$ Currently, this technique has been abandoned due to poor results. The gastrojejunostomy, another treatment option for this condition, also proved to be more susceptible to failure since it does not free the duodenal obstruction. Among surgical techniques, the one that has demonstrated greater effectiveness in solving symptoms has been the duodenojejunostomy. ${ }^{8,16}$ After the first successful laparoscopic duodenojejunostomy by Gersin et al. in $1998,{ }^{17}$ the procedure became the most common surgical treatment for this syndrome. ${ }^{15,18}$ Benefits of laparoscopic duodenojejunostomy include those of the minimally invasive approach along with better functional results. ${ }^{7,19}$

We can conclude that SMAS is a rare condition that requires a high level of suspicion. Patients should be approached by a multidisciplinary team, which leads to better diagnosis and treatment options. Laparoscopic duodenojejunostomy is the procedure of choice, when conservative treatment fails.

\section{References}

1. Salem A, Al Ozaibi L, Nassif S, Osman R, Al Abed N, Badri F. Superior mesenteric artery syndrome: A diagnosis to be kept in mind (Case report and literature review). International Journal of Surgery Case Reports 2017; 34: 84-86.

2. Sun Z, Rodriguez J, McMichael J, Walsh R, Chalikonda S, Rosenthal R, Kroh M, El-Hayek K. Minimally invasive duodenojejunostomy for superior mesenteric artery syndrome: a case series and review of the literature. Surgical Endoscopy 2015; 29 (5): 1137-1144.

3. Aneiros Castro B, Cano Novillo I, García Vázquez A, Martín Alelu R, Gómez Fraile A. Wilkie's syndrome in monozygotic twins treated by 3-D laparoscopic duodenojejunostomy. Asian Journal of Endoscopic Surgery 2018; 12 (1): 125-127. 
4. Iwaoka Y, Yamada M, Takehira Y, Hanajima K, Nakamura T, Murohisa G, Hirai R, Kitagawa M. Superior Mesenteric Artery Syndrome in Identical Twin Brothers. Internal Medicine 2001; 40 (8): 713-715.

5. Wilkie DP. Chronic duodenal ileus. Am J Med Sci 1927; 173: 643-649.

6. Kirby G, Faulconer E, Robinson S, Perry A, Downing R. Superior mesenteric artery syndrome: a single centre experience of laparoscopic duodenojejunostomy as the operation of choice. The Annals of The Royal College of Surgeons of England 2017; 99 (6): 472-475.

7. Barkhatov L, Tyukina N, Fretland A, Røsok B, Kazaryan A, Riis R, Edwin B. Superior mesenteric artery syndrome: quality of life after laparoscopic duodenojejunostomy. Clinical Case Reports 2017; 6 (2): 323-329.

8. Mathenge N, Osiro S, Rodriguez I, Salib C, Tubbs R, Loukas M. Superior mesenteric artery syndrome and its associated gastrointestinal implications. Clinical Anatomy 2013; 27 (8): 1244-1252.

9. Lamba R, Tanner D, Sekhon S, McGahan J, Corwin M, Lall C. Multidetector CT of Vascular Compression Syndromes in the Abdomen and Pelvis. RadioGraphics 2014; 34 (1): 93-115.

10. Buresh CT, Graber MA. Unusual causes of recurrent abdominal pain. Emerg Med 2016; 38 (5): 11-18.

11. Yakan S, Calıskan C, Kaplan H, Deneclı A, Coker A. Superior Mesenteric Artery Syndrome: A Rare Cause of Intestinal Obstruction. Diagnosis and Surgical Management. Indian Journal of Surgery 2012; 75 (2): 106-110.

12. Kawanishi K, Shojima K, Nishimoto M, Abe H, Kakimoto T, Yasuda Y, Hara T, Kato J. Superior Mesenteric Artery Syndrome May Be Overlooked in Women with Functional Dyspepsia. Internal Medicine 2017; 56 (19): 2549-2554.
13. Konen E, Amitai M, Apter S, Garniek A, Gayer G, Nass S, Itzchak Y. CT angiography of superior mesenteric artery syndrome. American Journal of Roentgenology 1998; 171 (5): 1279-1281.

14. Gustafsson L, Falk A, Lukes P, Gamklou R. Diagnosis and treatment of superior mesenteric artery syndrome. British Journal of Surgery 1984; 71 (7): 499-501.

15. Yao S. Minimally invasive surgery for superior mesenteric artery syndrome: A case report. World Journal of Gastroenterology 2015; 21 (45): 12970.

16. 16. Barchi L, Alves A, Jacob C, Caldas Bresciani C, Yagi O, Nogueira T, Cecconello I, Zilberstein B. Favorable minimal invasive surgery in the treatment of superior mesenteric artery syndrome: Case report. International Journal of Surgery Case Reports 2016; 29: 223-226.

17. Gersin KS, Heniford BT. Laparoscopic duodenojejunostomy for treatment of superior mesenteric artery syndrome. JSLS 1998; 2: 281-284.

18. Chang J, Boules M, Rodriguez J, Walsh M, Rosenthal R, Kroh M. Laparoscopic duodenojejunostomy for superior mesenteric artery syndrome: intermediate follow-up results and a review of the literature. Surgical Endoscopy 2016; 31 (3): 1180-1185.

19. Shinji S, Matsumoto S, Kan H, Fujita I, Kanazawa Y, Yamada T, Hagiwara N, Koizumi M, Onodera H, Ko K, Machida T, Uchida E. Superior mesenteric artery syndrome treated with singleincision laparoscopy-assisted duodenojejunostomy. Asian Journal of Endoscopic Surgery 2015; 8 (1): 67-70. 